\title{
Motivasi Karir, Motivasi Gelar, Persepsi Biaya Pendidikan, Parental Influence dan Minat Mengikuti PPAk
}

\author{
Rodame Munthe ${ }^{1}$ \\ Fakultas Ekonomi dan Bisnis \\ Universitas Udayana, Indonesia
}

\section{Anak Agung Ngurah Bagus Dwirandra² Fakultas Ekonomi dan Bisnis Universitas Udayana, Indonesia}

Surel : rodamegtg15@gmail.com

\section{ABSTRAK}

Pendidikan profesi akuntansi itu penting karena bisa menghasilkan akuntan profesional, namun minat untuk mengikutinya saat ini masih rendah. Penelitian ini bertujuan untuk mengetahui pengaruh motivasi karir, motivasi gelar, persepsi biaya pendidikan, dan parental influence pada minat mengikuti pendidikan profesi akuntan. Populasinya adalah seluruh mahasiswa aktif akuntansi reguler pagi dan reguler sore FEB Unud angkatan 2017 sebanyak 287. Teknik pengumpulan sampel adalah metode purposive sampling. Jumlah sampel sebanyak 143 dengan metode pengumpulan data menggunakan kuesioner. Teknik analisis data adalah analisis regresi linear berganda. Hasil analisis menunjukkan bahwa motivasi karir dan motivasi gelar berpengaruh pada minat mengikuti pendidikan profesi akuntan, persepsi biaya pendidikan dan parental influence tidak berpengaruh pada minat mengikuti PPAk.

Kata Kunci: $\quad$ Motivasi Karir; Motivasi Gelar; Persepsi Biaya Pendidikan; Parental Influence; Pendidikan Profesi Akuntan.

\section{Career Motivation, Degree Motivation, Perception of Education Costs, Parental Influence and Interest in Participating in PPAk}

\begin{abstract}
Accounting profession education is important because it can produce professional accountants, but the interest in following it is currently still low. This study aims to determine the effect of career motivation, degree motivation, perceived cost of education, and parental influence on interest in pursuing accounting profession education. The population is all active students of accounting in the morning and evening regular FEB Unud class of 2017 as many as 287. The sample collection technique is the purposive sampling method. The number of samples is 143 with the data collection method using a questionnaire. The data analysis technique is multiple linear regression analysis. The results of the analysis show that career motivation and degree motivation have an effect on interest in attending accounting profession education, perceptions of educational costs and parental influence have no effect on interest in PPAK.

Keywords: $\quad$ Career Motivation; Degree Motivation; Perceptions of Education Costs; Parental Influence; Accountant Professional Education.
\end{abstract}

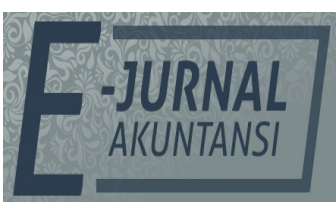

e-ISSN 2302-8556

Vol. 31 No. 8

Denpasar, Agustus 2021

Hal. 2128-2141

DOI:

10.24843/EJA.2021.v31.i08.p19

PENGUTIPAN:

Munthe, R., \& Dwirandra, A.A.N.B. (2021). Motivasi

Karir, Motivasi Gelar, Persepsi Biaya Pendidikan, Parental Influence dan Minat Mengikuti PPAk. E-Jurnal Akuntansi, 31(8), 2128-2141

RIWAYAT ARTIKEL: Artikel Masuk: 2 Juni 2021 Artikel Diterima: 5 Agustus 2021

Artikel dapat diakses : https://ojs.unud.ac.id/index.php/Akuntansi/index 


\section{PENDAHULUAN}

Manusia dituntut harus dapat memenuhi kebutuhan hidupnya. (Widiyani \& Badera, 2019) mengungkapkan dalam teori kebutuhan hierarki bahwa kebutuhan manusia berdasarkan suatu hierarki kebutuhan dari kebutuhan yang paling rendah hingga kebutuhan yang paling tinggi. Kebutuhan hidup dapat terpenuhi dengan melakukan suatu usaha. Salah satu bentuk usaha tersebut adalah bekerja. Pekerjaan menjadi faktor penting dan melatarbelakangi dipilihnya pendidikan yang mampu membuat seseorang mudah memperoleh pekerjaan dan mendapat gaji yang lebih besar. Salah satu jurusan yang menjadi primadona karena banyaknya lowongan kerja yang membutuhkan lulusannya adalah jurusan akuntansi. Motivasi memilih jurusan akuntansi karena adanya anggapan bahwa akuntan di masa yang akan datang memiliki peluang yang besar untuk bekerja.

Pendidikan Profesi Akuntan (PPAk) telah dijelaskan pada UU No.2/1989 serta UU No.34/1954. Dalam UU tersebut dapat disimpulkan pendidikan profesi akuntan merupakan pendidikan tambahan bagi seorang lulusan program sarjana ekonomi pada Program Studi Akuntansi yang ingin mendapatkan gelar akuntan. Berdasarkan Surat Keputusan (SK) Mendiknas No. 179/U/2001, lulusan sarjana Strata 1 (S1) akuntansi berkesempatan untuk menempuh Pendidikan Profesi Akuntan di Perguruan Tinggi yang telah ditunjuk oleh Direktoral Jendral Pendidikan Tinggi. Mereka yang telah selesai menempuh Pendidikan Profesi Akuntan (PPAk) berhak memperoleh gelar sebutan profesi akuntan (Ak). Adapun profil perkembangan jumlah mahasiswa pendidikan profesi akuntan Fakultas Ekonomi dan Bisnis Universitas Udayana dari angkatan XXVI-XXXII (Periode Tahun 2017- 2020) dapat disimak pada Tabel 1.

Tabel 1. Perkembangan Jumlah Mahasiswa Pendidikan Profesi Akuntan Fakultas Ekonomi dan Bisnis Universitas Udayana Tahun 2017-2020

\begin{tabular}{cccc}
\hline Tahun Akademik & Angkatan & $\begin{array}{c}\text { Jumlah Mahasiswa } \\
\text { Mendaftar }\end{array}$ & $\begin{array}{c}\text { Jumlah Mahasiswa } \\
\text { Diterima }\end{array}$ \\
\hline \multirow{2}{*}{2017} & XXVI & 15 & 14 \\
& XXVII & 17 & 16 \\
2018 & XXVIII & 20 & 19 \\
& XXIX & 25 & 25 \\
2019 & XXX & 16 & 15 \\
2020 & XXXI & 26 & 20 \\
& XXXII & 19 & 19 \\
\hline
\end{tabular}

Sumber: Data Penelitian, 2021

Tabel 1, dapat dilihat bahwa pada angkatan XXVI sampai angkatan XXIX mengalami kenaikan jumlah mahasiswa yang mendaftar dan jumlah mahasiswa diterima. Sedangkan dari angkatan XXX sampai angkatan XXXII mengalami penaikan dan penurunan atau fluktuasi jumlah mahasiwa. Ini terlihat bahwa minat untuk meningkatkan profesionalisme di tengah tingginya kebutuhan dan tuntutan peningkatan profesionalisme akuntan dengan mengikuti pendidikan profesi akuntan masih rendah. Banyak faktor-faktor yang memengaruhi minat mahasiswa untuk mengikuti pendidikan profesi akuntan. Beberapa diantaranya adalah banyak mahasiswa yang tidak tertarik untuk mengikuti pendidikan profesi akuntan khususnya lulusan mahasiswa akuntansi. Ada mahasiswa lulusan akuntansi yang mengatakan sudah cukup dengan gelar S.E saja dan melanjutkan 
bekerja tanpa mengikuti pendidikan profesi akuntan. Masalah ini memunculkan indikasi bahwa terdapat perbedaan motivasi dan persepsi setiap mahasiswa akuntansi untuk mengikuti pendidikan profesi akuntan. Banyak juga mahasiswa yang mengatakan bahwa mereka tertarik mengikuti pendidikan profesi akuntan namun mereka terbentur masalah biaya pendidikan yang memang tidak sedikit. Selain itu, dukungan dari orang sekitar termasuk orang tua juga sangat penting.

Motivasi karir adalah dorongan yang timbul dari dalam diri seseorang untuk senantiasa meningkatkan kemampuan pribadinya dalam rangka mencapai kedudukan, jabatan atau karir yang lebih baik dari sebelumnya (Kepemimpinan et al., 2004). Semakin besar motivasi yang dimiliki maka dapat meningkatkan kualitas dan kemampuan yang dimiliki. Penelitian yang dilakukan oleh (Fajarsari, 2020) dan (Dewi \& Ratnadi, 2018) menyatakan bahwa motivasi karir berpengaruh positif dan signifikan terhadap minat mahasiswa akuntansi mengikuti Pendidikan Profesi Akuntan (PPAk).

Motivasi gelar adalah dorongan dalam diri untuk menunjukkan kemampuan seseorang yang berprofesi di bidang akuntansi. Penelitian yang dilakukan oleh (Vesperalis \& RM, 2017) dan (Jeniari \& Dwija, 2019) menunjukkan bahwa semakin kuat keinginan seseorang untuk mendapatkan gelar resmi yang diakui oleh negara dan masyarakat maka semakin berminat seseorang tersebut mengikuti PPAk.

Persepsi biaya pendidikan merupakan sebuah proses saat individu mengatur dan menginterpretasikan kesan-kesan sensoris mereka terhadap keseluruhan pengorbanan finansial yang dikeluarkan baik oleh orang tua mahasiswa atau mahasiswa tersebut untuk keperluan selama menempuh pendidikan dari awal sampai berakhirnya pendidikan. Penelitian yang dilakukan oleh (Widiyani \& Badera, 2019) dan (Dewi \& Ratnadi, 2018) menunjukkan bahwa biaya pendidikan berpengaruh positif pada minat mahasiswa mengikuti pendidikan profesi akuntansi di Universitas Udayana. Penelitian tersebut bertentangan dengan penelitian yang dilakukan oleh (Aryani \& Erawati, 2016) dan (Permana \& Suartana, 2018) biaya pendidikan berpengaruh negatif pada minat mahasiswa mengikuti PPAk.

Parental influence adalah pengaruh argumentasi orang tua terhadap anak dalam menempuh pendidikan untuk mencapai masa depan. Penelitian yang dilakukan oleh (Lukman \& Juniati, 2017), dan (Hermawan \& Tyas, 2019) mengemukakan bahwa parental influence merupakan faktor yang menentukan mahasiswa memilih melanjutkan pendidikan profesi kemungkinan karena dorongan orang tua yang kuat.

Pendidikan profesi akuntan adalah suatu usaha yang memiliki tujuan untuk menghasilkan akuntan profesional dengan memiliki daya saing ditingkat global dengan kualitas dan karakteristik yang sesuai (Bawono et al., 1999). Lulusan pendidikan profesi akuntan ini akan menjadi akuntan yang berhak mendapatkan Register Negara dan boleh mengikuti Ujian Sertifikat Akuntan Publik (USAP).

Motivasi karir mempunyai peran yang cukup besar dalam menentukan minat seseorang dalam mengikuti pendidikan profesi akuntan. Pendidikan profesi akuntan penting bagi mahasiswa akuntansi yang telah lulus, sebab pendidikan profesi akuntan dapat memberikan kontribusi untuk menjadi seorang akuntan yang profesional. Oleh karena itu motivasi yang memberikan dorongan semangat 
dari dalam diri mahasiswa sangat diperlukan guna menggugah minat mahasiswa akuntansi untuk mengikuti pendidikan profesi akuntan. Dalam teori hirarki kebutuhan Maslow dikatakan bahwa salah satu kebutuhan yang ingin dipenuhi oleh manusia adalah kebutuhan akan penghargaan meliputi faktor-faktor internal seperti harga diri, otonomi, dan prestasi, serta faktor-faktor eksternal seperti status, pengakuan dan perhatian. Hal ini didukung oleh penelitian (Fajarsari, 2020) dan (Dewi \& Ratnadi, 2018) yang menyatakan bahwa motivasi karir berpengaruh positif dan signifikan terhadap minat mahasiswa akuntansi mengikuti Pendidikan Profesi Akuntan (PPAk).

$\mathrm{H}_{1}$ : Motivasi karir berpengaruh positif pada minat mengikuti pendidikan profesi akuntan.

Gelar ialah identitas seseorang atas keahliannya dalam ilmu tertentu. Yang membedakan gelar S.E dengan gelar S.Ak ialah gelar S.Ak lebih menunjukkan kualifikasi serta spesifikasi seseorang yang memiliki profesi di bidang akuntansi dibandingkan seseorang lulusan S1 akuntansi yang bergelar S.E. Dalam teori hirarki kebutuhan Maslow dikatakan bahwa salah satu kebutuhan yang ingin dipenuhi oleh manusia adalah kebutuhan akan penghargaan meliputi faktorfaktor internal seperti harga diri, otonomi, dan prestasi, serta faktor-faktor eksternal seperti status, pengakuan dan perhatian. Hal ini didukung oleh penelitian (Vesperalis \& RM, 2017) dan (Jeniari \& Dwija, 2019) yang mengatakan bahwa semakin kuat keinginan seseorang untuk mendapatkan gelar resmi yang diakui oleh negara dan masyarakat maka semakin berminat seseorang tersebut mengikuti PPAk.

$\mathrm{H}_{2}$ : Motivasi gelar berpengaruh positif pada minat mengikuti pendidikan profesi akuntan.

Persepsi biaya pendidikan merupakan sebuah proses saat individu mengatur dan menginterpretasikan kesan-kesan sensoris mereka terhadap keseluruhan pengorbanan finansial yang dikeluarkan baik oleh orang tua mahasiswa atau mahasiswa tersebut untuk keperluan selama menempuh pendidikan dari awal sampai berakhirnya pendidikan. Teori hukum permintaan menjelaskan tentang adanya hubungan yang bersifat negatif yaitu, apabila harga naik maka jumlah barang yang diminta sedikit dan apabila harga rendah jumlah barang yang diminta meningkat. Berdasarkan hukum ekonomi tersebut, dikatakan bahwa manusia ingin mendapatkan keuntungan yang setinggitingginya dengan biaya yang serendah-rendahnya. Biaya yang harus dikeluarkan untuk mendapat gelar akuntan jauh lebih besar dibandingkan biaya untuk mendapat gelar sarjana ekonomi (S1). Hal tersebut tentu menjadi faktor terbesar yang menjadi penghalang atau penghambat minat seseorang untuk mengikuti pendidikan profesi akuntan. Hal ini didukung oleh penelitian (Widiyani \& Badera, 2019) dan (Dewi \& Ratnadi, 2018) menunjukkan bahwa biaya pendidikan berpengaruh positif pada minat mahasiswa mengikuti pendidikan profesi akuntansi di Universitas Udayana. Berbeda dengan penelitian dari (Aryani \& Erawati, 2016) dan (Permana \& Suartana, 2018) biaya pendidikan berpengaruh negatif pada minat mahasiswa mengikuti PPAk.

$\mathrm{H}_{3}$ : Persepsi biaya pendidikan berpengaruh negatif pada minat mengikuti pendidikan profesi akuntan. 
Parental Influence melatarbelakangi minat mahasiswa yang ingin mengikuti pendidikan profesi akuntan. Orang tua adalah teladan yang dikagumi oleh seorang anak dari kecil, termasuk kesuksesan mulai dari mengenal dunia hingga memilih pendidikan demi masa depannya. Terkadang kebingungan dan ketidakmampuan anak untuk memilih pilihan yang sulit membuat orang tua tergerak untuk mengarahkan anak-anak mereka. Dalam hal pendidikan seorang anak, latar belakang pendidikan orang tua serta harapan orang tua terhadap masa depan anaknya menjadi salah satu pengaruh tersendiri bagi pendidikan mereka. Dalam teori hirarki kebutuhan Maslow dikatakan bahwa salah satu jenis kebutuhan individu adalah kebutuhan aktualisasi diri yaitu dorongan untuk menjadi seseorang sesuai dengan kecakapannya meliputi pertumbuhan, pencapaian, potensi seseorang, dan pemenuhan kebutuhan diri sendiri. Penelitian yang dilakukan oleh (Lukman \& Juniati, 2017), dan (Hermawan \& Tyas, 2019) mengemukakan bahwa parental influence merupakan faktor yang menentukan mahasiswa memilih melanjutkan pendidikan profesi kemungkinan karena dorongan orang tua yang kuat.

$\mathrm{H}_{4}$ : Parental influence berpengaruh positif pada minat mengikuti pendidikan profesi akuntan.

\section{METODE PENELITIAN}

Lokasi penelitian ini bertempat di Fakultas Ekonomi dan Bisnis Universitas Udayana yang beralamat di Jl. P.BSudirman, Denpasar. Populasi dalam penelitian adalah seluruh mahasiswa aktif program studi S1 Akuntansi di Fakultas Ekonomi dan Bisnis Universitas Udayana angkatan 2017 yakni sejumlah 287 mahasiswa. Metode penentuan sampel dalam penelitian ini menggunakan non probability sampling dengan teknik purposive sampling dan diperoleh sampel penelitian sebanyak 143 sampel. Metode pengumpulan data menggunakan kuisioner berbasis internet. Kuisioner pada penelitian ini dibagikan dalam bentuk google form melalui group line mahasiswa akuntansi angkatan 2017 sejumlah 287 responden yang merupakan keseluruhan dari populasi, kemudian akan dipilah untuk memperoleh sampel yang sesuai dengan kriteria. Dalam penelitian ini, peneliti menggunakan jenis instrumen kuesioner dengan pemberian skor. Untuk menguji kualitas data yang diperoleh dari penerapan instrumen, maka dilakukan uji validitas dan uji reliabilitas. Teknik analisis data yang digunakan dalam penelitian ini adalah teknik analisis regresi linier berganda. Sebelum melakukan pengujian regresi, terdapat beberapa asumsi yang harus dipenuhi agar data yang akan dimasukkan dalam model regresi telah memenuhi ketentuan dan syarat dalam regresi. Uji asumsi klasik dalam penelitian ini mencakup uji normalitas, multikolinearitas, dan heteroskedastisitas. Tahapan analisis dalam penelitian ini yaitu, Analisis Statistik Deskriptif, Uji Asumsi Klasik, Analisis Regresi Linear Berganda, Analisis Koefisien Determinasi (R²), Uji Kelayakan Model (Uji F), dan Uji Hipotesis. Model regresi linier berganda dirumuskan sebagai berikut.

$\hat{Y}=\alpha+\beta_{1} X_{1}+\beta_{2} X_{2}+\beta_{3} X_{3}+\beta_{4} X_{4}+\varepsilon \ldots \ldots$

Keterangan:

$\hat{Y} \quad=$ Minat mengikuti PPAk

a $\quad=$ Konstanta

$\beta 1=$ Koefisien regresi motivasi karir 


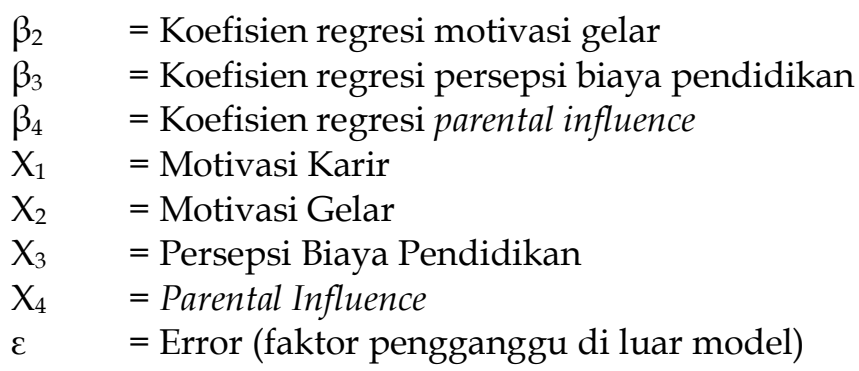

\section{HASIL DAN PEMBAHASAN}

Rincian penyebaran dan pengembalian kuesioner disajikan pada Tabel 2, Secara keseluruhan menunjukkan bahwa jumlah kuesioner yang disebarkan adalah sebanyak 167 kuesioner dan seluruhnya telah dikembalikan. Dari kuesioner yang dikembalikan tersebut tidak ada yang gugur, sehingga dapat digunakan seluruhnya.

Tabel 2. Analisis Sampel Menggunakan Purposive Sampling

\begin{tabular}{ll}
\hline Keterangan & Jumlah \\
\hline Total kuesioner yang disebar & 167 \\
Kuesioner yang tidak dikembalikan & 0 \\
Kuesioner yang dikembalikan & 167 \\
Kuesioner yang gugur (tidak sesuai kriteria) & 0 \\
Kuesioner yang digunakan & 167 \\
Tingkat Pengembalian (response rate) $=167 / 167 \times 100 \%$ & $100 \%$ \\
Tingkat penggunaan $($ usable response rate) $=167 / 167 \times 100 \%$ & $100 \%$ \\
\hline
\end{tabular}
Sumber: Data Penelitian, 2021

Namun, setelah dilakukan pengolahan data terdapat data outlier pada 24 responden. Adanya data outlier pada saat pengolahan data akan menyebabkan data tidak berdistribusi normal sehingga harus dikeluarkan dari pengamatan. Peneliti melakukan outlier data agar mendapatkan data yang berdistribusi secara normal sehingga menyebabkan pengamatan berkurang menjadi 143 responden. Karakterisitik responden dalam penelitian ini meliputi program, jenis kelamin, usia, status pekerja, penerima beasiswa, dan sumber dana kuliah responden.

Uji validitas dilakukan dengan menghitung korelasi antara skor masingmasing butir pertanyaan dengan total skor sehingga didapat nilai Pearson Correlation. Hasil uji validitas menunjukkan bahwa semua instrumen penelitian yang digunakan untuk mengukur variabel penelitian memiliki nilai koefisien korelasi diatas 0,30 sehingga keseluruhan indikator yang digunakan dinyatakan valid dan layak digunakan sebagai instrumen penelitian. Pengujian reliabilitas atau keandalan instrumen menunjukan sejauh mana suatu pengukuran kembali terhadap gejala yang sama.

Hasil pengujian reliabilitas menunjukkan bahwa seluruh instrumen penelitian memiliki koefisien Cronbach's Alpha lebih dari 0,70. Jadi dapat dikatakan bahwa seluruh variabel dalam penelitian ini telah memenuhi syarat reliabilitas atau kehandalan sehingga dapat digunakan untuk melakukan penelitian. Hasil analisis statistik deskriptif menunjukkan bahwa banyaknya kuesioner yang diolah adalah 143 kuesioner untuk masing-masing variabel yang dapat dideskripsikan sebagai berikut. 
Tabel 3. Hasil Analisis Statistik Deskriptif

\begin{tabular}{lccccc}
\hline Variabel & N & Min & Max & Mean & $\begin{array}{c}\text { Std. } \\
\text { Deviation }\end{array}$ \\
\hline Motivasi Karir & 143 & 2,00 & 4,00 & 3,428 & 0,506 \\
Motivasi Gelar & 143 & 1,60 & 4,00 & 3,032 & 0,549 \\
Persepsi Biaya Pendidikan & 143 & 1,00 & 4,00 & 2,650 & 0,709 \\
Parental Influence & 143 & 1,00 & 4,00 & 2,671 & 0,760 \\
Minat Mahasiswa Mengikuti PPAk & 143 & 2,00 & 4,00 & 3,383 & 0,493 \\
\hline
\end{tabular}

Sumber: Data Penelitian, 2021

Nilai minimum variabel motivasi karir mengikuti pendidikan profesi akuntan adalah 2,00, nilai maksimum sebesar 4,00, nilai rata-rata atau mean sebesar 3,428, dan nilai standar deviasi sebesar 0,506. Pada Tabel 3, dapat dilihat nilai rata-rata mendekati nilai maksimum yakni sebesar 4,00. Hal ini berarti motivasi karir dari responden yang digunakan dalam penelitian tergolong tinggi. Nilai minimum variabel motivasi gelar mengikuti pendidikan profesi akuntan adalah 1,60, nilai maksimum sebesar 4,00, nilai rata-rata atau mean sebesar 3,0322, dan nilai standar deviasi sebesar 0,549. Pada Tabel 3, dapat dilihat nilai rata-rata mendekati nilai maksimum yakni sebesar 4,00. Hal ini berarti motivasi gelar dari responden yang digunakan dalam penelitian tergolong tinggi. Nilai minimum variabel persepsi biaya pendidikan adalah 1,00 , nilai maksimum sebesar 4,00 , nilai rata-rata atau mean sebesar 2,650, dan nilai standar deviasi sebesar 0,709. Pada Tabel 3, dapat dilihat nilai rata-rata mendekati nilai maksimum yakni sebesar 4,00. Hal ini berarti persepsi biaya pendidikan dari responden yang digunakan dalam penelitian tergolong tinggi. Nilai minimum variabel parental influence adalah 1,00, nilai maksimum sebesar 4,00, nilai rata-rata atau mean sebesar 2,6713, dan nilai standar deviasi sebesar 0,760 . Pada Tabel 3, dapat dilihat nilai rata-rata mendekati nilai maksimum yakni sebesar 4,00. Hal ini berarti parental influence dari responden yang digunakan dalam penelitian tergolong tinggi. Nilai minimum variabel minat mengikuti PPAk adalah 2,00, nilai maksimum sebesar 4,00, nilai rata-rata atau mean sebesar 3,383, dan nilai standar deviasi sebesar 0,4936. Pada Tabel 3, dapat dilihat nilai rata-rata mendekati nilai maksimum yakni sebesar 4,00. Hal ini berarti minat mengikuti PPAk dari responden yang digunakan dalam penelitian tergolong tinggi.

Tabel 4. Hasil Uji Asumsi Klasik

\begin{tabular}{lcccc}
\hline \multirow{2}{*}{$\begin{array}{l}\text { Parameter Yang } \\
\text { Diuji }\end{array}$} & Uji Normalitas & \multicolumn{2}{c}{ Uji Multikolinearitas } & Uji \\
\cline { 2 - 5 } & Asymp. Sig (2-tailed) & Tolerance & VIF & Sig. \\
\hline Unstandarized & 0,085 & & & \\
$\begin{array}{l}\text { Residual } \\
\text { Motivasi karir }\end{array}$ & 0,629 & 1,590 & 0,108 \\
Motivasi gelar & 0,416 & 2,404 & 0,252 \\
Persepsi biaya & 0,660 & 1,515 & 0,327 \\
pendidikan & & & \\
Parental Influence & 0,613 & 1,632 & 0,627 \\
\hline
\end{tabular}

Sumber: Data Penelitian, 2021

Nilai residual dinyatakan berdistribusi normal apabila nilai Asymp.sig (2tailed) lebih besar dari a $(0,05)$. Berdasarkan hasil uji normalitas pada Tabel 4, diperoleh nilai Asymp.sig (2-tailed) sebesar 0,085 lebih besar dari a $(0,05)$. Hal ini 
menunjukkan data penelitian ini berdistribusi normal. Hasil uji multikolinearitas diperoleh hasil bahwa variabel dalam penelitian ini memiliki nilai tolerance $>0,10$ atau nilai VIF < 10, sehingga dapat disimpulkan bahwa variabel yang digunakan dalam penelitian ini terbebas dari multikolinearitas atau tidak terdapat korelasi antar variabel independen. Nilai signifikansi dari variabel motivasi karir, motivasi gelar, persepsi biaya pendidikan, dan parental influence masing-masing memiliki nilai yang lebih besar dari 0,05 yang berarti tidak terdapat pengaruh antara variabel bebas terhadap absolute residual. Dengan demikian, dapat disimpulkan bahwa tidak terjadi gejala heteroskedastisitas pada model regresi dalam penelitian ini.

Tabel 5. Hasil Analisis Regresi Linear Berganda

\begin{tabular}{|c|c|c|c|c|c|c|}
\hline \multirow{2}{*}{\multicolumn{2}{|c|}{ Model }} & \multicolumn{2}{|c|}{$\begin{array}{l}\text { Unstandardized } \\
\text { Coefficients }\end{array}$} & \multirow{2}{*}{$\begin{array}{l}\text { Standardized } \\
\text { Coefficients } \\
\text { Beta }\end{array}$} & \multirow{2}{*}{ Sig } & \multirow{2}{*}{$\begin{array}{l}\text { Hasil Uji } \\
\text { Hipotesis }\end{array}$} \\
\hline & & B & $\begin{array}{l}\text { Std. } \\
\text { Error }\end{array}$ & & & \\
\hline \multirow[t]{9}{*}{1} & (Constant) & 3,463 & 0,988 & & 0,001 & \multirow{4}{*}{$\begin{array}{l}\mathrm{H}_{1} \text { diterima } \\
\mathrm{H}_{2} \text { diterima } \\
\mathrm{H}_{3} \text { ditolak }\end{array}$} \\
\hline & Motivasi Karir & 0,360 & 0,048 & 0,518 & 0,000 & \\
\hline & Motivasi Gelar & 0,276 & 0,076 & 0,307 & 0,000 & \\
\hline & Persepsi Biaya & 0,081 & 0,058 & 0,093 & 0,166 & \\
\hline & Pendidikan & & & & & \multirow{2}{*}{$\mathrm{H}_{4}$ ditolak } \\
\hline & Parental Influence & $-0,022$ & 0,056 & $-0,027$ & 0,695 & \\
\hline & $\begin{array}{l}\text { Adjusted } R \\
\text { Square }\end{array}$ & & & & & 0.591 \\
\hline & F Hitung & & & & & 49,791 \\
\hline & Signifikansi F & & & & & 0,000 \\
\hline
\end{tabular}

Sumber: Data Penelitian, 2021

Berdasarkan hasil analisis regresi linier berganda pada Tabel 5, maka model prediksi regresi sederhana adalah sebagai berikut.

$$
\hat{Y}=3,463+0,360 X_{1}+0,276 X_{2}+0,081 X_{3}-0,022 X_{4}
$$

Nilai konstanta (a) sebesar 3,463 memiliki arti bahwa apabila nilai variabel motivasi karir $\left(X_{1}\right)$, motivasi gelar $\left(X_{2}\right)$, persepsi biaya pendidikan $\left(X_{3}\right)$, dan parental influence $\left(\mathrm{X}_{4}\right)$ dianggap konstan pada nilai nol (tetap atau tidak ada perubahan), maka mahasiswa tetap memiliki minat untuk mengikuti pendidikan profesi akuntan. Nilai koefisien motivasi karir $\left(X_{1}\right)$ sebesar 0,360 memiliki arti bahwa jika motivasi karir $\left(X_{1}\right)$ meningkat sebesar satu satuan persepsi maka minat mahasiswa untuk mengikuti PPAk (Y) akan meningkat sebesar 0,360 satuan persepsi, dengan asumsi variabel bebas lainnya konstan. Nilai koefisien motivasi gelar $\left(\mathrm{X}_{2}\right)$ sebesar 0,276 memiliki arti bahwa jika motivasi gelar $\left(X_{2}\right)$ meningkat sebesar satu satuan persepsi maka minat mahasiswa untuk mengikuti PPAk (Y) akan meningkat sebesar 0,276 satuan persepsi, dengan asumsi variabel bebas lainnya konstan. Nilai koefisien persepsi biaya pendidikan $\left(X_{3}\right)$ sebesar 0,081 memiliki arti bahwa jika persepsi biaya pendidikan $\left(X_{3}\right)$ meningkat sebesar satu satuan persepsi maka minat mahasiswa untuk mengikuti PPAk (Y) akan meningkat sebesar 0,081 satuan persepsi, dengan asumsi variabel bebas lainnya konstan. Nilai koefisien parental influence $\left(\mathrm{X}_{4}\right)$ sebesar -0,022 memiliki arti bahwa jika parental influence $\left(\mathrm{X}_{4}\right)$ mengalami kenaikan satu satuan persepsi maka minat mahasiswa untuk mengikuti PPAk (Y) akan mengalami penurunan sebesar -0,022 satuan persepsi, dengan asumsi variabel bebas lainnya konstan. 
Hasil uji kelayakan model pada Tabel 5, dapat dilihat bahwa nilai dari Uji F sebesar 49,791 dengan signifikansi sebesar 0,000. Hal ini berarti bahwa signifikansi pada uji F nilainya lebih kecil dari 0,05 , sehingga dapat disimpulkan bahwa model regresi yang dibuat layak digunakan sebagai alat analisis untuk menguji pengaruh variabel independen terhadap variabel dependen. Hasil ini mempunyai arti bahwa ada pengaruh signifikan antara motivasi karir, motivasi gelar, persepsi biaya pendidikan, dan parental influence secara simultan pada minat mahasiswa mengikuti pendidikan profesi akuntan. Tabel 5, diketahui bahwa nilai R Square sebesar 0,591 atau 59,1 persen. Hal ini berarti bahwa sebesar 59,1 persen variansi minat mahasiswa untuk mengikuti pendidikan profesi akuntan dapat dijelaskan oleh variansi motivasi karir, motivasi gelar, persepsi biaya pendidikan, dan parental influence sedangkan sisanya sebesar 40,9 persen dipengaruhi oleh variabel lain yang tidak dijelaskan dalam model penelitian ini.

Berdasarkan hasil analisis menunjukkan bahwa motivasi karir berpengaruh positif pada minat mengikuti pendidikan profesi akuntan. Hal ini memiliki makna bahwa semakin kuat dorongan dari dalam diri mahasiswa dalam meningkatkan kemampuan pribadi dan dalam mencapai kedudukan atau karir yang lebih baik, maka minat mahasiswa dalam mengikuti pendidikan profesi akuntan juga akan meningkat. Hal ini menandakan hipotesis pertama $\left(\mathrm{H}_{1}\right)$ dalam penelitian ini diterima. Mayoritas mahasiswa akuntansi melihat bahwa pendidikan profesi akuntan sebagai salah satu sarana pendidikan untuk meningkatkan karir mereka. (Dewi \& Ratnadi, 2018) mengungkapkan bahwa auditor yang memiliki dasar pendidikan akuntan profesional hanya perlu waktu yang lebih pendek untuk dipromosikan sebagai auditor senior atau manajer. Penelitian ini sesuai dengan teori hierarki kebutuhan yang dikemukakan oleh Abraham Maslow. Teori ini menyatakan bahwa motivasi seseorang dapat didorong akibat adanya keinginan untuk memenuhi kebutuhan akan penghargaan yang berkaitan dengan reputasi dan prestasi. Hasil penelitian ini searah dengan penelitian sebelumnya yang dilakukan oleh (Aryani \& Erawati, 2016), (Sari et al., 2017), (Indrawati, 2009), (Sriantari et al., 2017), dan (Permana \& Suartana, 2018) yang menyatakan bahwa motivasi karir berpengaruh positif dan signifikan terhadap minat mengikuti pendidikan profesi akuntan.

Berdasarkan hasil analisis menunjukkan bahwa motivasi gelar berpengaruh positif pada minat mengikuti pendidikan profesi akuntan. Hal ini memiliki makna bahwa semakin tinggi motivasi untuk mendapatkan gelar Ak maka semakin tinggi minat untuk mengikuti pendidikan profesi akuntan. Hal ini menandakan hipotesis kedua $\left(\mathrm{H}_{2}\right)$ dalam penelitian ini diterima. Gelar merupakan identitas mengenai keahlian seseorang dalam bidang ilmu tertentu. Semakin banyak gelar yang dimiliki maka menunjukan semakin berkualitas pendidikan yang dimiliki seseorang tersebut. Mahasiswa akuntansi Fakultas Ekonomi dan Bisnis Universitas Udayana beranggapan bahwa gelar Ak lebih menunjukan kualitas dan spesifikasi seseorang dibandingkan dengan seseorang lulusan S1 akuntansi yang bergelar S.E. Penelitian ini sesuai dengan teori hierarki kebutuhan yang dikemukakan oleh Abraham Maslow pada salah satu poin dari 5 hierarki kebutuhan yang telah dikemukakan yaitu kebutuhan penghargaan (Esteem needs), yang meliputi kebutuhan akan perhargaan prestasi yang telah diraih, kebutuhan akan rasa hormat, dan pengakuaan atas kemampuan, dan keahlian 
yang dimiliki, serta kebutuhan akan status dan kedudukan. Hasil penelitian ini didukung oleh penelitian sebelumnya yang dilakukan oleh (Sari et al., 2017), (Vesperalis \& RM, 2017), dan (Jeniari \& Dwija, 2019) yang menyatakan bahwa motivasi gelar berpengaruh positif dan signifikan pada minat mengikuti pendidikan profesi akuntan.

Berdasarkan hasil analisis menunjukkan bahwa persepsi biaya pendidikan tidak berpengaruh pada minat mengikuti pendidikan profesi akuntan. Hal ini memiliki makna bahwa semakin sesuai biaya pendidikan maka akan meningkatkan minat mengikuti pendidikan profesi akuntan. Begitu juga sebaliknya apabila biaya pendidikan tidak sesuai maka akan menurunkan minat mengikuti pendidikan profesi akuntansi. Hal ini menandakan hipotesis ketiga $\left(\mathrm{H}_{3}\right)$ dalam penelitian ini ditolak. Keadaan ekonomi mahasiswa akuntansi dapat dikatakan relatif mapan. karena tidak mempermasalahkan biaya pendidikan yang relatif mahal. Mahasiswa akuntansi Fakultas Ekonomi dan Bisnis Universitas Udayana angkatan 2017 memiliki persepsi bahwa pendidikan yang bermutu akan memiliki biaya pendidikan yang relatif mahal. Penelitian ini tidak mampu mengkonfirmasi teori hukum permintaan yang dikemukakan oleh Alfred Marshall yang menjelaskan tentang adanya hubungan yang bersifat negatif yaitu, apabila harga naik maka jumlah barang yang diminta sedikit dan apabila harga rendah jumlah barang yang diminta meningkat. Hasil penelitian ini searah dengan penelitian sebelumnya yang dilakukan oleh (Dewi \& Ratnadi, 2018) dan (Widiyani \& Badera, 2019) yang menyatakan bahwa persepsi biaya pendidikan pengaruh positif pada minat mengikuti pendidikan profesi akuntan.

Berdasarkan hasil analisis menunjukkan bahwa parental influence tidak berpengaruh pada minat mengikuti pendidikan profesi akuntan. Hal ini memiliki makna semakin tinggi nilai parental influence yang dihasilkan maka semakin rendah minat mahasiswa akuntansi untuk mengikuti pendidikan profesi akuntan. Begitu pula sebaliknya, semakin rendah nilai parental influence yang dihasilkan maka semakin tinggi minat mahasiswa akuntansi untuk mengikuti pendidikan profesi akuntan. Hal ini menandakan hipotesis keempat $\left(\mathrm{H}_{4}\right)$ dalam penelitian ini ditolak. Dalam penelitian ini mahasiswa akuntansi memiliki tipe mandiri artinya sudah bisa menentukan masa depannya sendiri. Namun dari hasil penelitian ini dapat dilihat bahwa nilai sig lebih besar dari nilai alpha yang berarti walaupun mahasiswa akuntansi dapat dikatakan mandiri tetapi masih mendengarkan dan meminta masukan dari orangtuanya. Hasil penelitian ini tidak mampu mengkonfirmasi teori pengharapan yang dikemukakan oleh Victor Vroom, dimana dalam teori pengharapan dinyatakan bahwa motivasi seseorang terkandung dari harapan yang akan diperolehnya pada masa depan. Hasil penelitian ini bertentangan dengan penelitian yang dilakukan oleh (Lukman \& Juniati, 2017), dan (Hermawan \& Tyas, 2019) yang menyatakan bahwa parental influence merupakan faktor yang menentukan mahasiswa memilih untuk melanjutkan pendidikan profesi yang kemungkinan dorongan orang tua yang kuat. Sementara, hasil penelitian ini sejalan dengan penelitian (Ardhiyati, 2019) yang menjelaskan bahwa faktor pengaruh orangtua tidak penting atau tidak berpengaruh terhadap pemilihan karir sebagai akuntan publik oleh mahasiswa. Sehingga dapat disimpulkan bahwa parental influence dalam penelitian ini tidak 
berpengaruh terhadap minat mahasiswa akuntansi untuk mengikuti pendidikan profesi akuntan.

\section{SIMPULAN}

Motivasi karir berpengaruh positif pada minat mahasiswa untuk mengikuti pendidikan profesi akuntan. Hal ini berarti bahwa semakin tinggi motivasi mahasiswa untuk meningkatkan karirnya maka minat mengikuti pendidikan profesi akuntan akan semakin bertambah. Motivasi gelar berpengaruh positif pada minat mengikuti pendidikan profesi akuntan. Hal ini berarti bahwa semakin tinggi motivasi untuk meningkatkan gelarnya maka minat untuk mengikuti pendidikan profesi akuntan akan semakin bertambah. Persepsi biaya pendidikan tidak berpengaruh pada minat mengikuti pendidikan profesi akuntan. Hal ini berarti bahwa semakin mahal dan tidak terjangkau persepsi biaya pendidikan yang dibebankan pada mahasiswa maka minat mengikuti pendidikan profesi akuntan akan semakin meningkat. Parental influence tidak berpengaruh pada minat mengikuti pendidikan profesi akuntan. Hal ini berarti bahwa semakin rendah nilai parental influence yang dihasilkan maka semakin tinggi minat mengikuti pendidikan profesi akuntan.

Nilai $\mathrm{R}^{2}$ pada penelitian ini sebesar 0,591 persen yang berarti bahwa hanya 59,1 persen variansi minat mengikuti pendidikan profesi akuntan dapat dijelaskan oleh variabel bebas yang digunakan dalam model penelitian ini, sedangkan sisanya sebesar 40,9 persen dipengaruhi oleh variabel lain di luar model penelitian. Oleh karena itu, penelitian selanjutnya diharapkan menambahkan variabel-variabel bebas lain yang dapat memengaruhi minat untuk mengikuti pendidikan profesi akuntan seperti faktor internal lainnya, faktor sosial maupun faktor strategis komunikasi yang meliputi sosialisasi, seminar, pameran dan lain sebagainya agar nantinya dapat mengetahui tindakan apa yang harus dilakukan dalam upaya meningkatkan minat mahasiswa mengikuti pendidikan profesi akuntan di Universitas Udayana. Bagi program studi Pendidikan Profesi Akuntan (PPAk) sebaiknya merancang program maupun strategi agar dapat menarik minat mahasiswa untuk mengikuti pendidikan profesi akuntan. Peneliti selanjutnya juga disarankan untuk memperluas populasi yang digunakan agar hasilnya dapat digeneralisasi secara luas.

\section{REFERENSI}

Ajzen, I. (1991). The Theory of Planned Behavior. Journal of Organizationaaaaal Behavior and Human Decision Processes, Jurnal. Vol. 50. No. 2, h. 179-211.

Alimuddin, M. Z. N., Sjahruddin, H., \& Idris, M. H. (2014). Persepsi Mahasiswa Strata Satu Akuntansi Terhadap Pendidikan Profesi Akuntansi ( PPAk ) ( Studi Pada Universitas Hasanuddin Makassar ). E- Library STIE YPBUP Bongaya, JULY 2014, 1-13.

Alniacik, Umit, Esra Alniacik, Kultigin Akcin, dan Serhat Erat. (2012). Relationships between Career Motivation, Affective Commitment and Job Satisfaction. Procedia Social and Behavioral Science, 5(8), pp: 355-362.

Anak Agung Ayu Dewi Vesperalis, \& RM, K. M. (2017). Pengaruh Motivasi Pada Minat Sarjana Akuntansi Universitas Udayana Untuk Mengikuti Ppak. EJurnal Akuntansi, 19, 1691-1718. 
Ardhiyati, W. (2019). Pengaruh Nilai Intrinsik, Parental Influence, Motivasi, Persepsi, Penghargaan Finansial Dan Pertimbangan Pasar Kerja Terhadap Minat Menjadi Akuntan Publik (Studi Empiris pada Mahasiswa Prodi Akuntansi Fakultas Ekonomi Universitas Berkarakter Islam se-DIY).

Aryani, N. P. D., \& Erawati, N. M. A. (2016). Pengaruh Motivasi Kualitas, Karir, Ekonomi, Dan Biaya Pendidikan Pada Minat Mahasiswa Mengikuti Pendidikan Profesi Akuntansi. E-Jurnal Akuntansi, 16(1), 362-384.

Bawono, I. R., Novelsyah, M., \& Lutfia, A. (1999). Reguler Dan Non Reguler. 185193.

Buss, David, M. (1997). Human Social Motivation in Evolutionary Perspective: Grounding TerrorManagement Theory. Psychological Inquiry, 8 (1). pp: 22-26.

Carpenter, C.G dan R.H. Strawser. (1970). Job Preferences Selection of Accounting Students. Journal of Accountancy, pp:84-86.

Crow, L Dan Crow, A. (1986). Psikologi Pendidikan (Terjemahan Kasijan). Surabaya: Bina Ilmu.

Delfitri, S. Y. (2016). Pengaruh Motivasi Karir dan Persepsi Mahasiswa terhadap Minat untuk Mengikuti Pendidikan Profesi Akuntansi (PPAK) (Studi Empiris Pada Universitas Mahaputra Muhammad yamin solok). Jusie, I, 87-

Dewi, K. A. R., \& Ratnadi, N. M. D. (2018). Pengaruh Motivasi, Biaya, dan Pengetahuan Mahasiswa Tentang UU No. 5 Tahun 2011 Pada Minat PPak. EJurnal Akuntansi, 22(5), 51. https://doi.org/10.24843/EJA.2018.v22.i01.p03.

Eline, Gideon. (2009). Factors Affecting the Motivation on Interest Students to Participate an Accounting Profession Education. African Journal of Businiess Etich, 4(1), pp: 46-5.

Fajarsari, H. (2020). Pengaruh Motivasi dan Persepsi Terhadap Minat Mahasiswa Mengikuti Pendidikan Profesi Akuntansi (PPAK) di Kota Semarang. Pamator Journal, 13(1), 30-43. https://doi.org/10.21107/ pamator.v13i1.7001.

Ghozali, I. (2016). Aplikasi Analisis Multivariete dengan Program IMB SPSS 23 (8th ed.). Semarang: Badan Penerbit Universitas Diponegoro.

Hadiprasetyo, Teguh. (2014). Pengaruh Motivasi, Persepsi Biaya Pendidikan, dan Persepsi Masa Studi Terhadap Minat Mahasiswa Prodi Akuntansi Fakultas Ekonomi Universitas Negeri Yogyakarta Untuk Mengikuti Pendidikan Profesi Akuntansi. Jurnal Profita. 2(7)

Hall,Richard. (1968). Professionalism and Bureaucratization. American Sosiological Review Journal, 33(1), pp: 92-104.

Hansen, Don R dan Maryanne M.Mowen. (2009). Akuntansi Manajerial. Jakarta: Salemba Empat.

Hermawan, S., \& Tyas, F. I. W. N. (2019). Pengaruh Nilai Intrinsik, Parental Influence, dan Persepsi Mahasiswa dengan Pendekatan Theory Karier Anne Roe terhadap Pemilihan Karir sebagai Akuntan Publik bagi Mahasiswa Akuntansi Universitas Airlangga Surabaya. JABE (Journal of Applied Business and Economic), 5(2), 112. https://doi.org/10.30998/jabe.v5i2.2111

Jeniari, A. M., \& Dwija Putri, I. G. A. . A. (2019). Pengaruh Motivasi Pada Minat Mahasiswa Non Akuntansi Program Reguler Mengikuti Pendidikan Profesi $\begin{array}{llll}\text { Akuntansi. E-Jurnal } & \text { Akuntansi, } & 28(3), & \end{array}$ https://doi.org/10.24843/eja.2019.v28.i03.p07

Kamus Besar Bahasa Indonesia. (2008). Tim Penyusun Kamus Besar Bahasa 
Indonesia. (Edisi Pertama). Jakarta.

Kepemimpinan, P., Variabel, S., Hubungan, P., Organisasional, B., Keefektifan, D., Pasar, R., Terhadap, M., Pemilihan, H., Pergantian, D. A. N., Tahun, P., Dan, T., Citizenship, O., Sri, D., Widiastuti, W., Sc, M., \& Suryaningsum, S. (2004). Peran Kepemimpinan sebagai Variabel Pemoderasian Hubungan Budaya Organisasional dengan Keefektifan Organisasional. 1-77.

Keputusan Mendiknas No. 179/U/2001 Undang-undang No. 34 Tahun 1945 Tentang Pemakaian Gelar Akuntan.

Kermis, G., \& Kermis, M. (2013). Professional Presence and Soft Skills: a Roll for Accounting Education. Journal of Instructional Pedagogies, 14(8), 1-10.

Lubis, A. I. (2014). Akuntansi Keperilakuan (2nd ed.). Jakarta: Salemba Empat McClintock, C. G. (1972). Social Motivation- A set of propotions. Behavioral Sciene, 17(5), 438-454.

Lukman, H., \& Juniati, C. (2017). Faktor Yang Pengaruhi Pemilihan Karir Sebagai Akuntan Publik Bagi Mahasiswa Pts Wasta Dengan Pendekatan Reasoned $\begin{array}{llll}\text { Action Model. Jurnal Akuntansi, 20(2), } & 202 .\end{array}$ https://doi.org/10.24912/ja.v20i2.54

Marta Permana, I. M. B. A., \& Suartana, I. W. (2018). Pengaruh Motivasi Kualitas, Motivasi Karir, Motivasi Ekonomi, Motivasi Sosial, Biaya Pendidikan pada Minat Mengikuti PPAk. E-Jurnal Akuntansi, 25, 214. https://doi.org/10.24843/eja.2018.v25.i01.p09

Noe, R. A., Noe, A. W., \& Bachhuber, J. A. (1990). An Investigation of the Correlates of Career Motivation. Journal of Vocational Behavior, 37, 340- 356.

Noe, R. A., Noe, A. W., \& Bachhuber, J. A. (1990). An Investigation of the Correlates of Career Motivation. Journal of Vocational Behavior, 37, 340- 356.

Novita Indrawati. (2009). Motivasi Dan Minat Mahasiswa Untuk Mengikuti Pendidikan Profesi Akuntansi (PPAk). Pekbis Jurnal, 1(2), 124-130.

Nurhayani, U. (2012). Pengaruh Motivasi Terhadap Minat Mahasiswa Akuntansi untuk Mengikuti PPAk (PPAk) (Studi Empiris pada Perguruan Tinggi Swasta Medan). Jurnal Mediasi, 4(1), 59-67.

Paisey, N. J. C. (2006). Cutting to the core A reflection upon recent education poliey debates within the Institute of Chartered Accountants in England and Wales. The British Accounting Review Journal, 31-6.

Rialdi Azhar, Aulia Fuad, \& Erwin Saraswati. (2015). Motivation of Non Registered Auditor to Take Profession of Accountant Education (PPAk). IOSR Journal of Economics dan Finance, 6(5), pp: 40-48.

Robbins, Stephen P. \& Timothy A. Judge. (2008). Perilaku Organisasi Edisi ke- 12, Jakarta:Salemba Empat.

Sari, S. K., Andini, R., \& P., P. D. (2017). Faktor-Faktor Yang Mempengaruhi Minat Mahasiswa Akuntansi Untuk Mengikuti Pendidikan Profesi Akuntansi ( Ppak ). Jurnal Online Mahasiswa Fakultas Ekonomi Universitas Riau, 2(1).

Sriantari, N. K., Luh, N., \& Erni, G. (2017). ). Pengaruh Motivasi Dan Status Sosial Ekonomi Orang Tua Terhadap Minat Mahasiswa Akuntansi Untuk Mengikuti Putu Eka Dianita Marvilianti Dewi e-jurnal S1 Ak Universitas Pendidikan Ganesha. 1. 1.

Sugiyono. (2014). Metode Penelitian Bisnis (Pendekatan Kuantitatif, Kualitatif, dan RED). Bandung: Alfabeta 
Stole, S. D. (1976). Student's Views of The Public and Industrial Accountant. Journal of Accountancy, Pp:106-109.

Thomas et al. (1998). Quality Review, Continuing Professional Educatio Experince and Substandart Performance. AN Emperical Study:Journal of Accounting Horizons, 12(4)

Tracey Mc, Dowall \& Baverly Jackling. (2010). What Infuances Accounting Students' Attitudes Towards Accounting As a Profession?. Journal of Accounting Perception: Conference Proceeding, AFAANZ.

Umar, I. (2014). Factors Influencing Students' Career Choice in Accounting: The Case of Yobe State University. Research Journal of Finance and Accounting Vol.5. No.17

Venugopalan, O. (2007). Theories of Motivation: Maslow's Theory of Motivation its Relevance and Application among Non-Managerial Employees of Selected Public and Provate Sector Undertakings in Kerala. Thesis Department of Commerce \& Management Studies University of Calicut, 37- 60.

Vesperalis, A. A. A. D., \& RM, K. M. (2017). Pengaruh Motivasi pada Minat Sarjana Akuntansi Universitas Udayana untuk Mengikuti PPAk. E- Jurnal Akuntansi Universitas Udayana, 19(2), 1691-1718.

Weygant, 1 Donald E.Keiso and Paul D.Kimmel. (1996). Auditor Liability in The UK: The Case for Reform. Critical Perspectives on Accounting And Auditing. Vol 10 No. 3.

Wheeler, K.G. (1983). Perceptions of Labour Market Variables by College Student in Business, Education, and Psychology. Journal of Vocational Behavior, 22(2), $p p: 1-11$

Widiyani, N. L. I. A., \& Badera, I. D. N. (2019). Pengaruh Motivasi, Biaya Pendidikan Dan Lama Masa Studi Pada Minat Mahasiswa Mengikuti PPAk. E-Jurnal Akuntansi, 29(1), 188. https://doi.org/10.24843/eja.2019.v29.i01.p13 